\title{
Automatic virgin coconut oil (VCO) extractor
}

\author{
Fabian R. Tagle \\ BS Industrial Technology Department, Faculty of Polytechnic School, Isabela State University Cauayan Campus, Isabela \\ Philippines
}

\begin{abstract}
Virgin coconut oil (VCO) is a vegetable oil extracted from coconut milk that undergone either of the following extraction method: natural fermentation method with heat or without heat, expelling method or centrifugation method. Research showed that the extraction of VCO using expelling method had the highest percent oil recovery with $88.35 \%$ and yield of $30-31 \%$ followed by centrifugation method with oil recovery of $86.62 \%$ and yield of $31 \%$ then natural fermentation method with $65.95 \%$ oil recovery and yield of $16.5-19 \%$. Even with low percent oil recovery and yield, VCO producers here in the Philippines particularly in Quezon province still employs the natural fermentation among other extraction method of VCO due to its cost-effectivity. The natural fermentation method involves several manual scooping activities in removing the VCO from the other component of the coconut milk which also takes time of waiting for about 24 to 48 hours for the VCO to be fractioned from the coconut milk mixture. This research therefore, focused in improving the natural fermentation method by developing a machine that automatically extracts the VCO from the coconut milk with higher percent oil recovery and yield. The designed machine was evaluated based on its oil recovery, and yield with respect to the current method of extraction. Furthermore, the effects of temperature and maturity of coconut kernel to the machine's capability of extracting the VCO were carried out. The tests conducted showed that the Automatic Virgin Coconut Oil (VCO) Extractor had an oil recovery of $89.84 \%$. The study also showed that the yield using the automatic extractor is $31.27 \%$. It was also concluded that it is better to use the Automatic Virgin Coconut Extractor in the area with temperature of $35-37^{\circ} \mathrm{C}$ and preferably good coconut kernel should be used for the extraction of VCO.
\end{abstract}

\section{Introduction}

Virgin coconut oil productions were still considered as one of the promising industries in the country, since Philippines is one of the largest coconut producing countries in the world. It is simply because of the benefits that the oil could give such as: it could be used as raw materials for beauty enhancing products or even for products treating minor illnesses [1]. But what is virgin coconut oil? According to niulifekokonut pacific of Australia, the definition of virgin coconut oil depends on its processing method. They define virgin coconut oil as the oil produced from fresh coconut meat without the addition of enzyme/bacteria/additive and made without heat. And Mansor et al defined VCO as the oil from a coconut kernel through natural and mechanical means, either with or without the application of heat provided that there is no transformation of the oil. Generally, VCO could be extracted using the following processes: natural fermentation method with heat or without heat, expeller method, and centrifuge method [1,2]. And the common method of producing VCO in Quezon province is by natural fermentation method wherein the recovery of the oil employs series of manual scooping activities [3].
And according to studies, the VCO extraction was evaluated based on either yield or oil recovery. For the centrifugation method the oil recovery was $86.62 \%$, for the expelling method it was $88.35 \%$ and for the fermentation method, its oil recovery was $65.95 \%$.[1]. And the yield for centrifugation, expelling and fermentation method was $31 \%, 30-31 \%$, and $16.5-19 \%$ respectively [4].

Since the natural fermentation employs the manual separation of the oil by scooping it from the mixture, this study aimed to improve the oil recovery and yield of the fermentation method of producing VCO through automatic extraction of the oil from the other components of the coconut milk.

Specifically, the study sought to achieve the following objectives:

1. To design a machine that automatically extract the oil from the other components of the coconut milk.

2. To determine the effectiveness of the machine in recovering the $\mathrm{VCO}$ with respect to the manual scooping process.

3. To determine the effect of temperature in extracting VCO using the Automatic VCO Extractor. 
4. To determine the effect of the maturity of coconut in the extraction of VCO using the Automatic VCO Extractor.

\section{Methodology}

\subsection{Machine Design}

The Automatic Virgin Coconut Oil (VCO) Extractor was divided into two parts: the container design and the controller design. In designing the container, several factors were considered: the amount of coconut milk to be processed, the size of the container, and the materials to be used for the container. The size of the container was based from the amount of coconut milk that the container could handle. The material used for the container was stainless steel which is not chemically reactive to the virgin coconut oil. A glass strip was also inserted in order for the light of the sensor to pass through the VCO once it was fractioned in the mixture. The finished designed container undergone several testing to determine where the solenoid valve and through beam sensors should be placed

\subsection{Evaluation}

The Automatic Virgin Coconut Oil Extractor performance was evaluated based on: (1) the volume of oil that can be separated automatically (yield) and comparing the result with the yield of the manual scooping;(2) volume of VCO extracted at ambient temperature and at $35-37{ }^{\circ} \mathrm{C}$ temperature; (3) and volume of VCO extracted using good coconut kernel, green coconut kernel and matured coconut kernel.

The yield was computed based from the formula used by Y.C.Wong et. al. in their research Virgin Coconut Oil Production by Centrifugation Method.

Yield $=\left(\frac{\text { Volume of VCO extracted }}{\text { Volume of coconut milk }}\right) \times 100 \%$

The first activity was conducted in 5 trials and the model used was shown in Figure 1 as guide for the testing. One batch of coconut milk was brought to the Philippine Coconut Authority for laboratory test. And the VCO extracted from this same batch using both the manual scooping and automatic extractor were subjected to laboratory test at the Philippine Coconut Authority to determine if the machine contributes contaminants to the machine's output.

The extracted coconut milk was mixed with water with a ratio of 1:1 [4]. The first group undergone the automatic extraction and the other group passed on the manual scooping. Both method of extraction was conducted in a controlled room with temperature ranging from $35-37{ }^{\circ} \mathrm{C}$ [4]. And after 48 hours of natural fermentation, the volume of VCO for both group were measured using graduated cylinder. The average extracted $\mathrm{VCO}$ was computed using the the given formula.

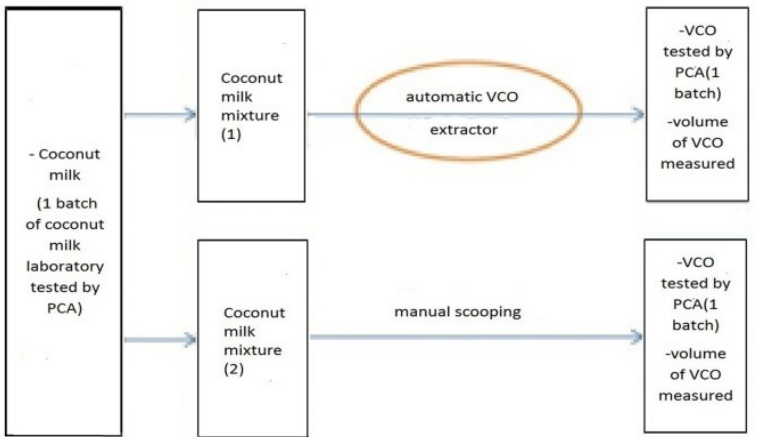

Figure 1.Automatic VCO Extrcator and Manual Scooping Test Process

Average volume of VCO $=\frac{\sum \text { Voil in cubic centimeters }}{5}$

For the oil recovery, the formula used to compute for the available oil in the mixture (Voil) was based from the container measurements. This principle of determing the available oil was based from the study of Nour et.al. [6].The formula was given as

Voil $=\pi r^{2}\left(h_{o i l}\right)-2(7.15)\left(h_{o i l}\right)$

where: $r$ - radius of the container

$\mathrm{h}_{\text {oil }}$ - height or thickness of the oil

And the percent oil recovery was computed by dividing the extracted oil by the available oil (Voil) times $100 \%$.

For the second activity, the machine was evaluated on the effect of temperature in extracting the VCO. The machine was tested in two scenarios; ambient $\left(28{ }^{\circ} \mathrm{C}\right)$ temperature and the $35-37{ }^{\circ} \mathrm{C}$ temperature (measured temperature range in the testing area). The required temperature for maximum yield of VCO is $35-40{ }^{\circ} \mathrm{C}[1]$ [4]. The activity was conducted in 5 trials for both temperature setting.

And for the third activity, the performance of the machine was tested using different types of coconut based on maturity; the good coconut kernel, green coconut kernel and matured coconut kernel. Good coconut kernels are those coconuts with brown husk, and with half full coconut water while green coconut kernels are coconuts with green husk and with full coconut water and matured coconut kernel are those coconuts with brown husk, almost empty coconut water and with haustorium (coconut shoot). The temperature in the testing area was $35-37{ }^{\circ} \mathrm{C}$. And 5 trials were conducted each for green coconut kernel and matured coconut kernel. And the data for good coconut kernel was already gathered in the previous activity.

\section{Results}

\subsection{VCO Settlement in the Container}

With the designed container, the location where the solenoid valve be placed as well as the through beam sensor were identified. From Table 1, the approximate volume of oil that could be extracted from the coconut milk mixture was shown. The average volume of VCO 
that could be separated from an input of $1900 \mathrm{ml}$ coconut milk is $661.43 \mathrm{ml}$.

Table 1. VCO Settlement in the Container

\begin{tabular}{|c|c|c|}
\hline Trials & $\begin{array}{c}\text { Thicknes } \\
\text { s of the } \\
\text { oil in cm }\end{array}$ & $\begin{array}{c}\mathrm{V}_{\text {oil }} \text { in } \\
\text { cubic } \\
\text { centimeters }\end{array}$ \\
\hline 1 & 10.8 & 660.20 \\
\hline 2 & 11.1 & 678.54 \\
\hline 3 & 10.8 & 660.20 \\
\hline 4 & 10.7 & 654.09 \\
\hline 5 & 10.7 & 654.09 \\
\hline \multicolumn{2}{|c|}{ Mean ( $\overline{\mathrm{X}})$} & 661.43 \\
\hline $\begin{array}{r}\text { Standard Deviation } \\
\text { (SD) }\end{array}$ & 10.04 \\
\hline
\end{tabular}

\subsection{Performance Evaluation of the Automatic Virgin Coconut Oil Extractor}

Automatic extraction

After selecting the good coconut kernel, cracking, grating and coconut milk extraction, $1900 \mathrm{ml}$ of water was added to the $1900 \mathrm{ml}$ extracted coconut milk. Good coconut kernel are those coconuts with brown coconut shell, good liquid sound when shake and no leak in any part of its shell. Shown in Table 2 is the summary of results for the good coconut kernel testing with fermentation temperature for 48 hours ranging from $35-37^{\circ} \mathrm{C}$.

Table 2. Volume of VCO and Yield Using the Automatic and Manual Extraction

\begin{tabular}{|c|c|c|c|c|}
\hline Trial & $\begin{array}{l}\text { Automatic } \\
\text { Extraction } \\
(\mathrm{ml})\end{array}$ & Yield & $\begin{array}{c}\text { Manual } \\
\text { Extraction } \\
(\mathrm{ml})\end{array}$ & Yield \\
\hline 1 & 595 & $31.32 \%$ & 512 & $26.95 \%$ \\
\hline 2 & 595 & $31.32 \%$ & 530 & $27.90 \%$ \\
\hline 3 & 605 & $31.84 \%$ & 519 & $27.32 \%$ \\
\hline 4 & 586 & $30.84 \%$ & 510 & $26.84 \%$ \\
\hline 5 & 590 & $31.05 \%$ & 521 & $27.42 \%$ \\
\hline $\bar{X}$ & 594.2 & $31.27 \%$ & 518.4 & $27.28 \%$ \\
\hline SD & 7.12 & & 7.96 & \\
\hline
\end{tabular}

Table 2 shows the yield results of the automatic extraction for five (5) trials. The average yield was $31.27 \%$. The data also revealed that it is normally distributed within the first sigma of the mean of volume extracted both for automatic and manual extraction.

Table 3 shows the results of the tests for the VCO percent oil recovery. The resulting Oil recovery of the automatic extraction of VCO with the fermentation method was $89.84 \%$. And the oil recovery of the fermentation method was $65.95 \%$ [1]. From these values, the Automatic VCO Extractor has improved the percent oil recovery of the VCO significantly.
Table 3. VCO Percent Oil Recovery

\begin{tabular}{|c|c|c|c|}
\hline $\begin{array}{c}\text { Tri } \\
\text { als }\end{array}$ & $\begin{array}{c}\text { VCO } \\
\text { Height } \\
(\mathrm{cm})\end{array}$ & $\begin{array}{c}\text { Volume } \\
\text { of VCO } \\
\text { Automati } \\
\text { cally } \\
\text { Extracted } \\
(\mathrm{ml})\end{array}$ & $\begin{array}{c}\text { Percent } \\
\text { Oil } \\
\text { Recover } \\
\mathrm{y}\end{array}$ \\
\hline 1 & 10.8 & 595 & $90.12 \%$ \\
\hline 2 & 11 & 595 & $88.49 \%$ \\
\hline 3 & 11 & 605 & $89.97 \%$ \\
\hline 4 & 10.7 & 586 & $89.59 \%$ \\
\hline 5 & 10.6 & 590 & $91.05 \%$ \\
\hline \multicolumn{2}{|c|}{ Mean } & 594.2 & $89.84 \%$ \\
\hline \multicolumn{2}{|c|}{ Standard } \\
Deviation
\end{tabular}

Manual Scooping

After selecting the good coconut kernel, cracking, grating and coconut milk extraction, $1900 \mathrm{ml}$ of water was added to the $1900 \mathrm{ml}$ extracted coconut milk. Shown in Table 2 is the summary of results for the good coconut kernel testing with fermentation temperature for 48 hours ranging from $35-37^{\circ} \mathrm{C}$. In this method of extraction, the curd above the VCO layer was set aside so that the VCO could be easily scooped. Careful and controlled scooping should be observed so that the curds and skim milk will not be scooped with the VCO.

Test 1 of Figure 2 shows the comparison between automatic extraction and manual scooping when it comes to volume of VCO extracted. It is noticeable that the automatic extraction has a significant difference in the amount of extracted VCO compared to manual scooping. In automatic extraction the mean of the volume of oil recovered was 594.2 while in manual scooping, it was $518.4 \mathrm{ml}$

For the second test. the coconut milk mixture is subjected to ferment at ambient temperature and compare it to VCO extracted at the required temperature of 35-37 ${ }^{\mathrm{O}} \mathrm{C}$. The data for the automatic extraction at the required temperature of $35-37^{\circ} \mathrm{C}$ was already gathered and stated on Test 2 of Figure 2 wherein the average volume of VCO extracted was $594.2 \mathrm{ml}$. While, the average volume of VCO extracted at ambient temperature of $28{ }^{\circ} \mathrm{C}$ was $483.2 \mathrm{ml}$. And the computed yield for the extraction at ambient temperature is $25.43 \%$ This results verified that temperature affect the VCO extraction.

For the third test, the Automatic Extractor was used to determine the volume of VCO that can be extracted if the coconut milk came from good coconut kernel, green coconut kernel and matured coconut kernel. The data for the automatic extraction of VCO with coconut milk from good coconut kernel was already gathered and indicated on Test 2 of Figure 2 wherein the average volume of VCO extracted was $594.2 \mathrm{ml}$. And with coconut milk coming from green coconut kernel, the VCO extracted was 384.2 $\mathrm{ml}$ while from matured coconut kernel, the $\mathrm{VCO}$ extracted 


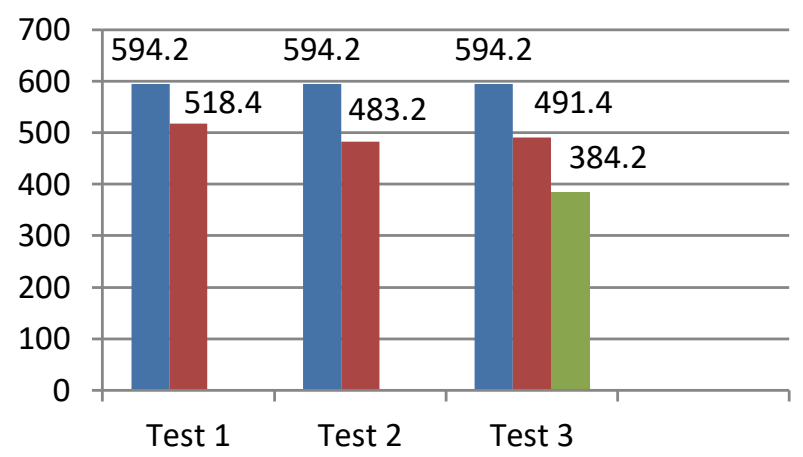

Figure 2. Graph of the Three Tests Conducted

was $491.4 \mathrm{ml}$. Among the three types of coconut kernel the green coconut kernel had the least amount of VCO extracted because it is young and the VCO is not yet fully grown at its kernel. The matured coconut kernel which already had a haustorium had a lesser amount of VCO extracted than the good coconut kernel because some of the VCO are already distributed to the other parts of the kernel (haustorium). And based from the VCO extracted and observations, the VCO from good coconut kernel generated higher yield than the green coconut kernel (20.21\%) and matured coconut kernel (25.86\%).

\section{Conclusions}

1. The Gizduino microcontroller together with relay circuit, through beam sensors, and solenoid valve comprises the design in extracting the virgin coconut oil automatically.

2. The results of testing revealed that the Automatic Virgin Coconut Oil (VCO) Extractor had an oil recovery of $89.84 \%$ and yield of $31.27 \%$ compared to the manual scooping with $65.95 \%$ and $27.28 \%$ respectively.

3. More VCO were extracted when the coconut milk mixture was fermented in the area with the required temperature of $35-37^{\circ} \mathrm{C}$ than the area with ambient temperature of $28^{\circ} \mathrm{C}$, The resulting volume of VCO are $594.2 \mathrm{ml}$ and $483.2 \mathrm{ml}$ respectively. And the yields are $31.27 \%$ for the automatic extraction at the required temperature and $25.43 \%$ for the ambient temperature.

4. The good coconut kernel could produce more VCO $(594.2 \mathrm{ml})$ with a yield of $31.27 \%$ compared to green coconut kernel $(384.2 \mathrm{ml})$ with a yield of $20.22 \%$ and matured coconut kernel $(491.4 \mathrm{ml})$ with a yield of $25.86 \%$.

\section{References}

1. Mansor, T.S.T., Che Man, Y.E., Shuhaimi, M, Abdul Afiq, M.J., \& Ku Nurul, F.K.M (2012). Physicochemical properties of virgin coconut oil extracted from different processing methods. Int. Fd. Rsrch. Jour. 19(3):837-845. Retrieved on November 16, 2015 from http://www.ifrj.upm.edu.my/19\%20(03)\%202012/(8)\%20I FRJ\%2019\%20(03)\%202012\%20Che\%20Man.pdf. (2012)
2. Santos, J. E. R., Villarino, B.N., Zosa A.R. \&Dayrit F.M. Analysis of Volatile Organic Compounds in Virgin Coconut Oil and their Sensory Attibutes. Phil. Jour. of Sci. ISSN 0031- 7683. Retrieved on December 10, 2015 from http://philjournal.dost.gov.ph/vol140no2/pdfs/Analysis\%2 0of $\% 20$ volatile $\% 20$ organic $\% 20$ compounds $\% 20$ in $\% 20$ VC O5.pdf. (2009)

3. "Coco Corporation formed in Lopez, Quezon". Retrieved on November 15, 2015 from http://www.prrm.org/news/coco-corporation-formed-inlopez-quezon.html

4. Bawalan, Divina ; Processing Manual for Virgin Coconut Oil, its Products and By-products for Pacific Island Countries and Territories. Retrived on November 12, 2015 from http://lrd.spc.int/publication/doc_download/1535processing-manual-for-vco-its-products-and-by-productsfor-picts--chapters-1-6. (2011).

5. Wong Y.C. \& Hartina Virgin Coconut Oil Production by Centrifugation Method. Retrieved on December 2, 2015 on http://www.orientjchem.org/pdf/vol30no1/OJCV030I01P2 37-245.pdf. (2014).

6. Nour,A. H., Mohammed, F.S., Yunus, R.M., and Arman, A. Demulsification of Virgin Coconut Oil by Centrifugation Method: A Feasibility Study. Retrieved on January 20, 2016 fromhttp://scialert.net/qredirect.php?doi=ijct.2009.59.64\& linkid=pdf. (2009).

7. Alicay, Calixto B. Research Methods and Techniques. (2014) 